\title{
Strategies for improving the sustainability of structural metals
}

https://doi.org/10.1038/s41586-019-1702-5

Received: 24 April 2019

Accepted: 25 September 2019

Published online: 6 November 2019

\author{
Dierk Raabe ${ }^{1 *}$, C. Cem Tasan ${ }^{2 *} \&$ Elsa A. Olivetti ${ }^{2 *}$
}

Metallic materials have enabled technological progress over thousands of years. The accelerated demand for structural (that is, load-bearing) alloys in key sectors such as energy, construction, safety and transportation is resulting in predicted production growth rates of up to 200 per cent until 2050. Yet most of these materials require a lot of energy when extracted and manufactured and these processes emit large amounts of greenhouse gases and pollution. Here we review methods of improving the direct sustainability of structural metals, in areas including reduced-carbon-dioxide primary production, recycling, scrap-compatible alloy design, contaminant tolerance of alloys and improved alloy longevity. We discuss the effectiveness and technological readiness of individual measures and also show how novel structural materials enable improved energy efficiency through their reduced mass, higher thermal stability and better mechanical properties than currently available alloys.

\section{Anniversary collection: go.nature.com/ nature150}

Structural metallic materials have a historic and enduring importance in our society. They have paved the path of human civilization with loadbearing applications that can be used under the harshest environmental conditions, from the Bronze Age onwards. Only metallic materials encompass such diverse features as strength, hardness, workability, damage tolerance, joinability, ductility and toughness, often combined with functional properties such as corrosion resistance, thermal and electric conductivity and magnetism. This versatility comes with a vast understanding of thermo-mechanical processing of metals (accrued over millennia of metals use), which in turn enable numerous production, manufacturing, design, repair and recycling pathways.

\section{Benefit and environmental impact of metallic alloys}

Metals have enabled multiple applications in the fields of energy conversion, transportation, construction, communication, health, safety and infrastructure. Examples over the millennia have been agricultural tools, manufacturing machinery, energy conversion engines and reinforcements in huge concrete-based infrastructures. Recent applications include structural alloys for weight reduction combined with high strength and toughness in the transportation sector ${ }^{1-4}$, efficient turbines operating at higher temperatures for power plants and air traffic $^{5,6}$, components for safe nuclear and fusion power and disposal ${ }^{7}$, targeted endurance or corrosive dissolution of biomedical implants ${ }^{8}$, embrittlement-resistant infrastructures for hydrogen-based industries ${ }^{9}$ or reusable spacecraft ${ }^{10}$. Metallurgical alloys and products boost innovation and economic growth: the global market for metals is about 3,000 billion euros per year ${ }^{11,12}$.

The success of the structural metals industry also means that it has an undisputable role in addressing our environmental crisis. The availability of metals (most of the elements used in structural alloys are among the most abundant), efficient mass producibility, low price and amenability to large-scale industrial production (from extraction to the metal alloy) and manufacturing (downstream operations after solidification) have become a substantial environmental burden: worldwide production of metals leads to a total energy consumption of about 53 exajoules $\left(10^{18} \mathrm{~J}\right)(8 \%$ of the global energy used) and almost $30 \%$ of industrial $\mathrm{CO}_{2}$-equivalent emissions (4.4 gigatons of carbon dioxide equivalent, $\mathrm{Gt} \mathrm{CO}_{2} \mathrm{eq}$ ) when counting only steels and aluminium alloys (the largest fraction of metal use by volume) ${ }^{13}$; see Table 1. Although the production volumes of nickel and titanium are much smaller, they have an eminent role in aerospace and biomedical materials and nickel is primarily used as an alloying element in stainless steel (accounting for two-thirds of nickel's uses). The worldwide annual production in terms of mass, energy and $\mathrm{CO}_{2}$ is presented in Table 1, with metal lost in manufacturing for these four key structural metals (where nickel use in stainless steel is the focus).

Mining and production of these materials have a huge impact in terms of resource use, emissions and waste generation, and this impact continues to grow, because of trends around urbanization, electrification and digitization (in 1950 less than $30 \%$ of the population lived in cities but this number is projected to exceed $60 \%$ by 2025 ). In addition, there are substantial byproducts of both industries that cause considerable environmental damage when not managed properly in perpetuity (losses throughout the supply chain are shown in Fig. 1 along with the quantities of material recovered as scrap). The two largest material groups (steel and aluminium) alone create huge mining and extraction byproducts, namely, 2,400 million tons (Mt) per year of tailings 
Table 1 | Overview of the energy and environmental impacts of key structural metals

\begin{tabular}{|c|c|c|c|c|}
\hline & Worldwide annual production (Mt $\left.\mathrm{yr}^{-1}\right)$ & Energy $\left(E J y^{-1}\right)$ & $\mathrm{CO}_{2}\left(\mathrm{CO}_{2}\right.$ eq $\left.\mathrm{yr}^{-1}\right)$ & Material scrapped in manufacturing \\
\hline Steel & 1,700 (of which $45 \%$ is based on scrap input) & 40 & $3.7 \mathrm{Gt}$ & $25 \%$ \\
\hline$\overline{\mathrm{Al}}$ & 94 (of which $30 \%$ is based on scrap input) & 13 & $0.7 \mathrm{Gt}$ & $40 \%$ \\
\hline $\mathrm{Ni}$ (stainless steels/superalloys) & 2.1 (of which $25 \%$ is based on scrap input) & 0.25 & $26 \mathrm{Mt}$ & $20 \%$ \\
\hline $\mathrm{Ti}$ & 0.2 (limited post-consumer scrap) & 0.07 & $6.7 \mathrm{Mt}$ & $60 \%$ \\
\hline
\end{tabular}

and $220 \mathrm{Mt}$ per year of slags for steels and $160 \mathrm{Mt}$ per year of bauxite residue for the case of aluminium.

Accidents, such as the iron-ore mining dam collapse in the mineralrich state of Minas Gerais, Brazil, in 2019 or the Ajka, Hungary, spill in 2010 where 100,000 cubic metres of red mud breached a dam, show that these byproducts provide a constant threat and risk associated with extraction of the precursors to structural alloys. These energyconsumption challenges and detrimental environmental impacts are the biggest obstacle for further use of structural metals (Table 1 and Fig. 1).

To outline the critical opportunities towards more sustainable structural metals, this Review describes several approaches and measures. We discuss direct sustainability effects for different steps along the value chain including $\mathrm{CO}_{2}$-reduced primary production, secondary production through recycling and more efficient manufacturing (see 'Direct sustainability measures' and 'From geo-mining to urban mining' sections). In this context, we also discuss opportunities to make alloy design more recycling-oriented upfront (see 'Sustainable alloy design and recycling-friendly materials' section). Another strategy focuses on improved alloy longevity through corrosion protection, damage tolerance and repairability for longer product use (see 'Longevity by corrosion protection, lifetime extension and re-use' section). Finally, we illustrate how structural metals also enable energy-efficient products and processes indirectly through improved energy conversion and weight reduction in transportation at present or higher safety and lower costs (see 'Higher energy efficiency through lightweighting and harsher operating conditions' section).

Frequently, addressing environmental impact involves tradeoffs and undesired consequences (such as vehicles not becoming more fuel-efficient despite materials innovation and the use of lightweight alloys because extra performance and luxury items are added). To ensure that we are improving sustainability outcomes, one must consider the environmental impact of these strategies quantitatively to avoid unintended consequences, wherein we improve one aspect at the detriment of another part of the material system or life cycle. Furthermore, one must consider the economic feasibility, the technology readiness of potential solutions, and the role of governmental legislation. Such legislation could mean that metal production will be limited by actions to limit greenhouse gas emissions. The scope of our discussion here primarily focuses on the technical aspects of proposed solutions, but we indicate the feasibility and viability of these opportunities, that is, we assess the effects that the different measures can have on enhancing the sustainability of structural alloys.

Figure 2 presents these critical opportunities along two axes, their scaled potential for impact versus their technology readiness. In Fig. 2 we qualitatively rank the impact of each of the strategies, in addition to how soon the impact might occur, based on the status of the technology (and societal willingness to adopt the approach). Each strategy is also differentiated by the metal industry where it may have the most impact (or not, if the potential impact is for all alloys). For the lower-volume alloys, containing mainly titanium and nickel, the qualitative impact potential is scaled by the size of the industry. For example, reduced scrap in manufacturing holds considerable potential for sustainability improvements within titanium-related value chains (green in Fig. 2) even though reductions in manufacturing scrap would have a higher impact overall for steel, given its larger production volumes. Irrespective of the qualitative nature of Fig. 2 and the subjective placement of each strategy, we offer this as a framework within which to understand the relative potential of each option.

\section{Direct sustainability measures}

Improving the direct sustainability of structural alloys refers to reducing the environmental footprint of production and manufacturing. Ideally, moving towards more sustainable materials can be coupled with improvement in the material's performance and longevity. In this section we focus on the opportunities within production first, and then within manufacturing.

As shown in Fig. 1, large fractions of metal still flow into societal stock (the infrastructure and products that we use), so efforts must focus first on production, where there is the most potential for reduction of carbon dioxide emissions. This means that recycling alone cannot address production efficiency because the world's demand for metallic alloys exceeds the available amount of scrap by about one-third, at least up to $2050^{13-16}$. Improvements in production will vary by metal, except that all production processes would benefit now from use of non-carbon-intensive energy sources and better byproduct management (particularly wastes from steel and aluminium), as we suggest in Fig. 2. These strategies are more technology-ready than $\mathrm{CO}_{2}$-reduced approaches. Another important approach across production of all metals (also shown in Fig. 2) lies in harvesting the enormous waste heat from metal production, which could be used for electricity production. We focus primarily on steel in our discussion on $\mathrm{CO}_{2}$-reduced production, with only a brief mention of aluminium, given that steel is where most of the opportunity exists (Fig. 2).

For low- and medium-alloyed carbon steels, coke-making, blast furnace operation and steel-making account for the largest fraction of $\mathrm{CO}_{2}$ emissions ( 2 billion tons) along the metal value chain, producing about $5.5 \%$ of the world's total $\mathrm{CO}_{2}$ emissions from all fossil fuel burning $^{17}$. A process with greatly reduced process emissions can be realized through electrolytic reduction of iron oxide in an alkaline solution at $110^{\circ} \mathrm{C}$ and subsequent processing in electric arc furnaces, realizing a fully electrified synthesis route. This approach is a disruptive alternative to carbon reduction in the blast furnace because it uses only electrical rather than fossil fuel as the energy carrier (this electricity must then come from renewable sources $)^{18}$. Up until now, wider use of this process has been impeded by the high costs and the aggressive conditions to which the electrodes are exposed. Technology readiness studies assume that electrolytic iron synthesis, which has not yet reached pilot-plant scale, is unlikely to enter the market before $2040^{19}$.

There are also steps that can be taken to render blast furnace and converter production more sustainable. A reduction in $\mathrm{CO}_{2}$ emissions of up to $30 \%$ can be reached through (1) the addition of hydrogen to fossil reducing agents (such as coal) in the blast furnace, which also increases efficiency and production rate as a result of hydrogen's high percolation rate ${ }^{20,21}$; and (2) $\mathrm{CO}_{2}$ capture and the downstream catalytic reduction of the waste $\mathrm{CO}_{2}$ into alternative chemical products and/or energy carriers ${ }^{22,23}$. These techniques are available and are currently being studied at pilot-plant scale. Whereas $\mathrm{CO}_{2}$ capture is ready to enter the market (depending on investment, carbon taxation and political decision-making to sanction this technique), the use of hydrogen in 

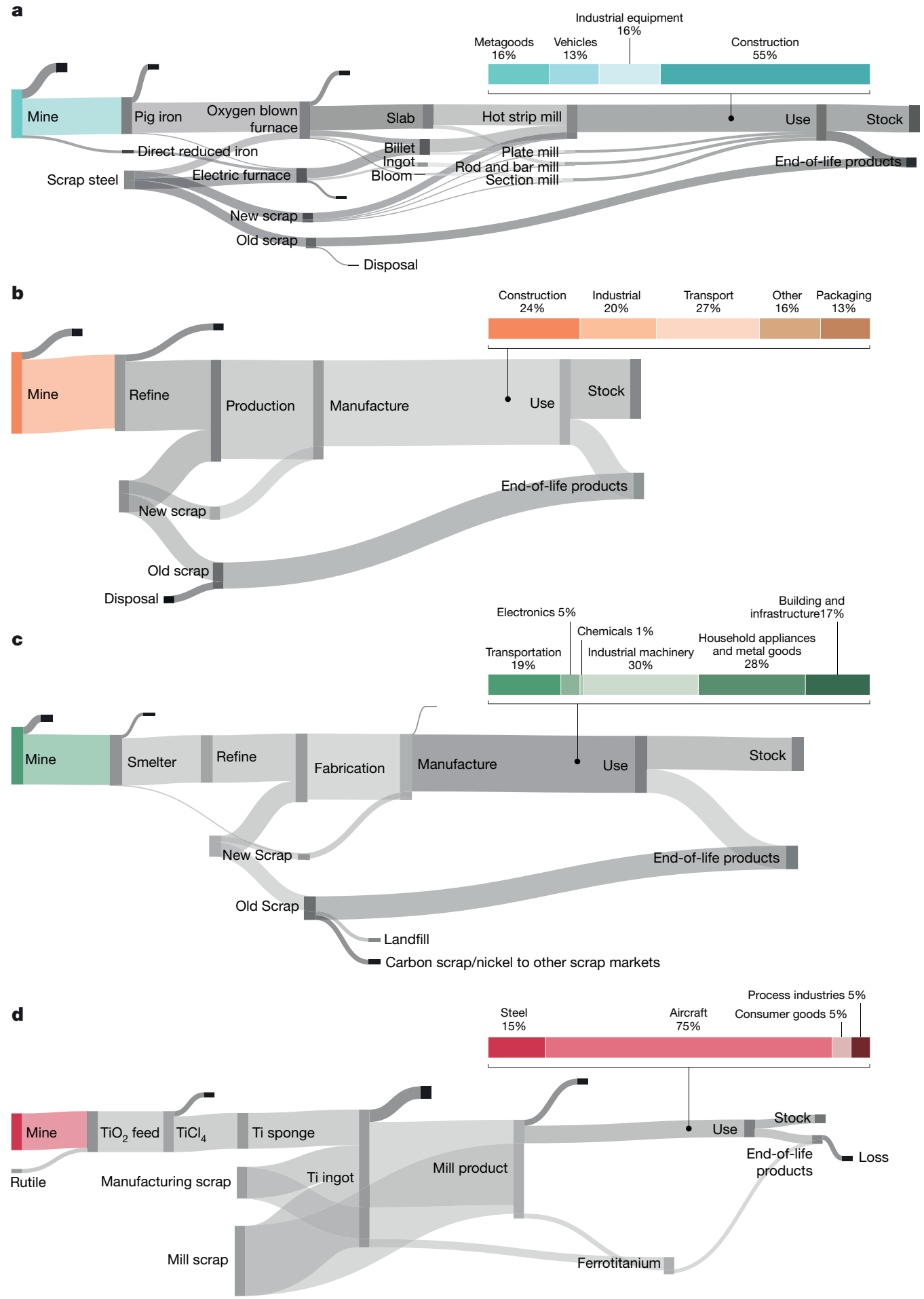

Fig. 1 Global material flows along the supply chain. Data from $2017^{150}$ are shown for iron and steel ${ }^{151}(\mathbf{a})$, aluminium ${ }^{150}(\mathbf{b})$, nickel $^{44}(\mathbf{c})$ and $\operatorname{titanium}^{46}(\mathbf{d})$. The width of the flows corresponds to mass at each stage including metal loss (not to scale). The inset charts show dominant end uses for these materials. This excludes use of titanium in the pigment sector (at present the largest sector at around $90 \%$ ) because our emphasis is on metals.

going through a liquid phase ${ }^{24}$. Traditionally, the reduction agents have been carbon carriers (such as methane) in this process. Nowadays, more complex gas mixtures can also be used, containing hydrogen, carbon monoxide and/or methane. Compared to traditional blast furnace ironmaking, $\mathrm{CO}_{2}$ emissions can be reduced through direct reduction by up to $50 \%$ depending on the hydrogen content of the used gas mixture. Hydrogen then acts as a reductant along with the carbon monoxide.

列 required catalysis processes challenging.

An alternative to the blast furnace is the solid-state reduction of ores. In these direct reduction methods, porous iron-oxide fillings are reduced into pelletized aggregates with $>95 \%$ Fe content without 


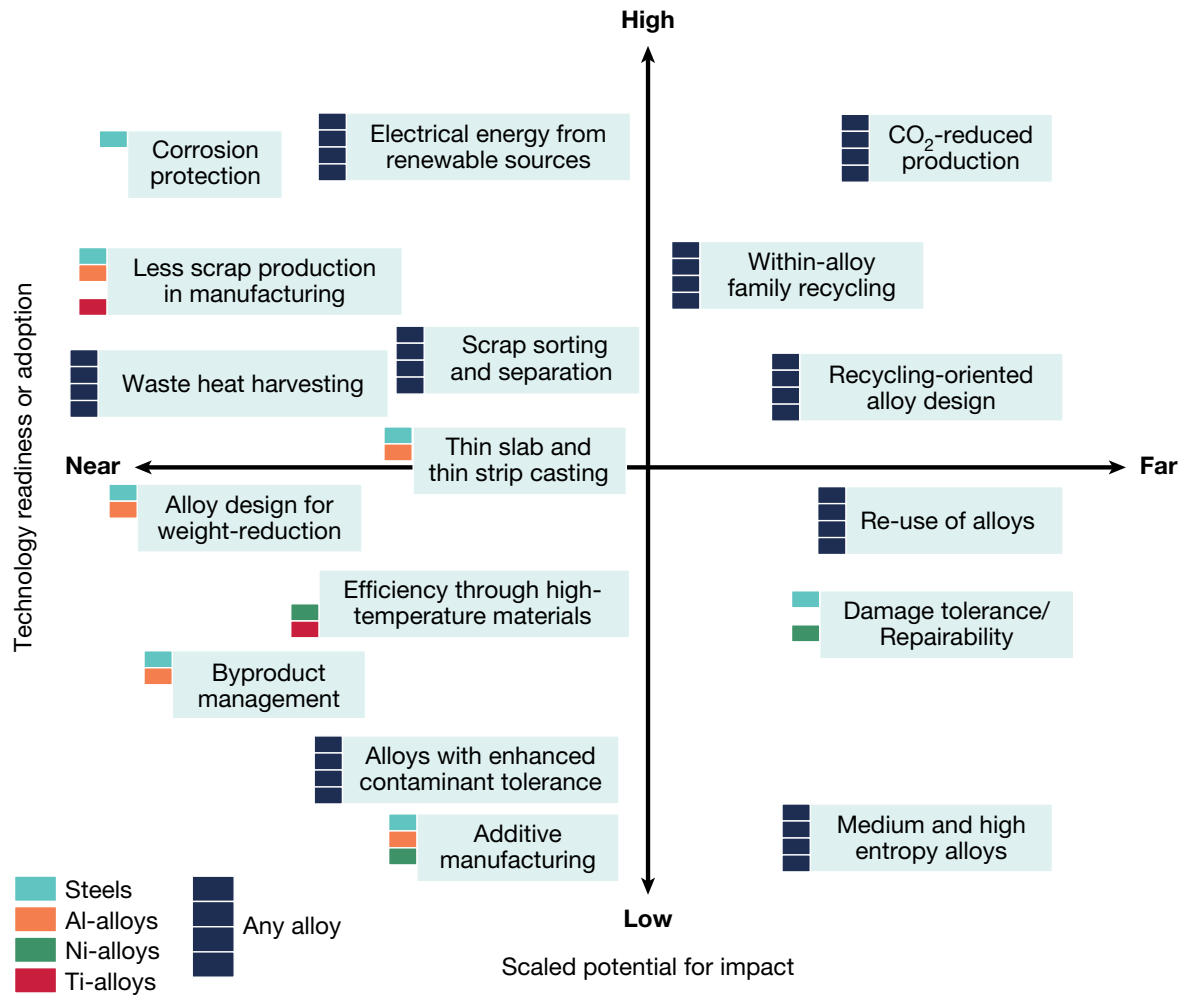

Fig. 2 | Impact and technology readiness of sustainability measures for structural alloys. We present an overview of several strategies and suggested potentials for impact on the sustainability of structural metals. Colours correspond to metals for which the opportunities are greatest (blue for carbon steel, orange for aluminium, green for nickel alloys and stainless steels, red for titanium). Where no colours are shown, all metals provide similar opportunities for that strategy. We include the qualitative potential (weighted by the relative scale of each industry) for each strategy by metal.
Hydrogen-enriched direct reduction is already available at industry scale. The competitive market entry of fully hydrogen-based direct reduction techniques without any $\mathrm{CO}_{2}$ emissions is currently being explored and expected to enter the market around $2030^{25}$. The primary reduction of aluminium is done via electrolysis so the main opportunities for improving its sustainability involve using renewable electricity sources (a strategy that would benefit all metals), improved efficiency of the electrolysis cells, and lower consumption rates of the currently used graphite or alternative-material electrodes ${ }^{26}$.

We next shift our attention downstream to manufacturing. In the downstream manufacturing following primary production, the overall yield losses occurring through liquid metal processing, forming and fabrication of aluminium and steel are $40 \%$ and $25 \%$ by mass, respectively ${ }^{27,28}$. These arise primarily from challenges involving the form of upstream products, the nature of upstream processing, the surface finish requirements, the supporting materials needed for shaping, and defects. Energy savings based on eliminating metal loss are estimated at around $5 \%$ and $15 \%$ for aluminium and steel, respectively. Alloy-specific high-quality material recovery already occurs inside casting and rolling plants where closed-loop procedures are established. Only a few producer-customer groups have established closed chains of returning alloy-specific scrap, so there are still substantial opportunities here that could be aided by data-driven approaches to process control and scrap sorting (see section 'From geo-mining to urban mining').

Near-net-shape manufacturing methods, where parts are cast or printed with a shape close to the final shape (thus requiring less machining) may provide an opportunity to reduce manufacturing material losses. Yet, additive manufacturing is not itself a sustainable synthesis approach owing to the high loss of powder, which can only be re-used a few times before it gets too oxidized (see Fig. 2 for the potential benefits of this strategy, most relevant for aluminium (Al), nickel (Ni) and titanium ( $\mathrm{Ti}$ ) alloys and tool steels) ${ }^{29}$. However, large-scale near-net-shape manufacturing methods have advanced. Examples are thin-slab and thin-strip casting of steels and aluminium (medium-term readiness and scaled impact; see Fig. 2). In conventional casters, steel slabs have a thickness of 150-300 mm. The usual target of a hot band thickness of $2-3 \mathrm{~mm}$ thus requires $>99 \%$ mechanical working, resulting in high energy and investment costs. Industrial thin-slab technology can provide slabs of thickness $25-60 \mathrm{~mm}$. For some steel grades, higher scrap fractions and higher contaminant content can be tolerated when casting thin slabs, owing to the high solidification rates (resulting in less segregation and fewer intermetallics forming). The next step is thinstrip steel casting ${ }^{30,31}$. In this approach, liquid steel is cast between two rolls and exposed to a hot reduction step to manufacture strips $2-3 \mathrm{~mm}$ thick that are directly coilable. The reduction in plastic work, energy and investment is enormous, yet production speed is slow and thin strips often do not reach the surface quality demanded by the market. Similar trends apply to strip production of aluminium alloys ${ }^{32,33}$. Several belt and twin roll techniques were developed, which are capable of casting aluminium strips with thickness $1-15 \mathrm{~mm}$. Specific challenges lie in the resulting centre-line segregation and the associated formation of coarse intermetallics, which are particularly caused by typical scrap contaminants such as iron ( $\mathrm{Fe}$ ) and silicon ( $\mathrm{Si}$ ). The manufacturing of high-quality and high-strength automotive grades, as a typical highend mass product, remains challenging.

\section{From geo-mining to urban mining}

One of the most efficient direct sustainability methods of reducing energy consumption and emissions lies in offsetting some primary extraction from geo-mined resources by urban mining of scraps and remelting them into new structural alloys. This can involve several specific strategies (outlined in Fig. 2) varying in readiness from scrap sorting and separation, to within-alloy family recycling (our preferred term for closed-loop recycling), alloy design for weight-reduction and 


\section{Review}

recycling-oriented alloy design. All have considerable opportunity to achieve a sustainable impact provided the market is responsive enough to offset some primary extraction ${ }^{34}$. The ability to do this effectively varies by alloy family and the source of the material (that is, whether it is post-industrial or post-consumer). By some measures for steel, particularly for the European Union and the USA, scrap availability is beginning to meet steel demand, so it will become critical to avoid contamination in recovery. Composition-sensitive steel recycling is a strategy that will offer more value than scrap-compatible steel design. Recovering post-consumer scrap requires the most sophisticated management practices and has the most room for improvement ${ }^{14}$ given that new material made from such scrap currently requires dilution with a large proportion of primary synthesized material in order to obtain the required composition. As the demand for products that can act as impurity sinks starts to decrease, we will have a smaller overall potential for recovery. Steel is typically recovered into the construction industry, a saturated market in some regions, and aluminium is recovered into cast products, so as the cast market becomes replete with scrap, the demand for cast products becomes a recovery limit ${ }^{35}$.

Advanced sorting moves the downcycling that is prevalent in metal recovery from the scrap yard to the plant floor. Automated probing and sorting methods have traditionally suffered from high costs resulting from low throughput and these costs are tightly constrained by the margins within recovery industries. Given the variety of type, shape, size, and form of scrap material, it has proved challenging to developing a wide array of broadly applicable recycling technologies. Such technology needs to cover identification, size reduction, separation, cleaning and material liberation. Separation steps include magnetic, sieving and air separation along with density separation, eddy-current, and spectroscopic techniques ${ }^{36}$. For these latter steps and even in scrapyard inspection, elemental analysers based on X-ray fluorescence and laser-induced breakdown spectroscopy have increasing potential. For instance, for certain alloys such as the more composition-sensitive aluminium-silicon-magnesium (Al-Si-Mg) alloy class, techniques such as aluminiumalloy separation by laser-inducedbreakdownspectroscopy are promising ways to screen and sort for specific doping elements such as iron and copper $(\mathrm{Cu})$. As alloys become more diverse, detection methods more sensitive, and throughput increases, these methods will become economically competitive ${ }^{37}$. When using such methods, the associated energy costs must be considered when comparing recycling to primary production ${ }^{38}$.

Until scrap sorting is perfected, the challenge for the use of secondary materials in a broader range of products is impurity tolerance, particularly as increased use of scrap may lead to compositional drift of alloy streams ${ }^{39}$. This compatibility and potential for drift is particularly important for aluminium alloys, where the thermodynamics of the remelting processes dictate the fate of associated alloying and tramp elements, possibly leading to the formation of undesired intermetallic phases. Only around $20 \%$ of end-of-life scrap is turned into wrought aluminium, even though wrought products account for two-thirds of all aluminium in use ${ }^{40}$. The reason for this discrepancy is that many Al-Si alloys, used for cast products, are particularly tolerant regarding high scrap usage whereas ductile-sheet-forming variants based on the Al-Mg and $\mathrm{Al}-\mathrm{Mg}$-Si systems are very sensitive to impurities.

Steel recycling is primarily done in an electric arc furnace, but also about $10-20 \%$ of ore-based steelmaking is from scrap (used for cooling in an oxygen converter). Steel production in an electric arc furnace has lower total energy consumption, enabling more flexible use of scrap materials ${ }^{41}$, but there is reduced flexibility regarding which alloys can be made because the refining reactions inside an electric arc furnace are challenging. One of the key limitations in steel recycling is that during the separation process there is incomplete separation of copper-containing components, an important contaminant in this downstream process. The copper content in a shredding process can be upwards of $0.25-0.3 \%$ (although, when copper prices rise, there is more incentive to manually handpick this material out of the stream). Tin can also cause downstream processing problems, particularly in combination with copper ${ }^{42}$.

As mentioned above, the material cycle for nickel is closely linked to that of stainless steel, and this manifests in its recovery too. Stainless steel can be either ferritic or austenitic. The recycling rate is much higher for austenitic stainless steel (nickel-containing) than for ferritic stainless steel. When recycled through a shredder plant, the ferritic stainless steel portion will be collected magnetically together with the ordinary carbon-steel scrap and will therefore be mixed into carbon steel. The stainless-steel scrap mixed into carbon-steel scrap was estimated to have reached $32 \%$ of postconsumer stainless-steel scrap flows in $2010^{43}$. Studies have estimated that $80 \%$ of postconsumer nickel scrap is recovered within the nickel cycle, whereas $20 \%$ becomes a constituent of carbon and copper scrap (and is not recovered as nickel ${ }^{44}$ ). Therefore, improving nickel recovery requires both avoiding its dissipation in carbon steels and the separation of low-nickel from high-nickel austenitic steels. Both measures are important for reducing nickel loss and avoiding nickel contamination of recycled carbon steel ${ }^{45}$.

Given the focus on titanium within the aerospace sector, there is considerable potential for recovery from scrap generated in the production process (Fig. 2; for example 100 tons of titanium alloy scrap is generated in making a frame for a 787 aeroplane). Because of the strict specifications within the industries in which titanium is used, the long-lived nature of those products (translating to a lack of economic incentive based on lack of post-use volume), and challenges around oxygen and iron impurities, essentially all titanium recycling is post-industrial ${ }^{46}$. Post-industrial material can be re-introduced into the remelting step of the primary route to make titanium ingots.

The challenge with improved titanium recycling even for industrial scrap is oxygen contamination, which can be decreased by remelting scrap with virgin titanium, but only up to a limit (particularly if demand grows). Novel processing technologies are focused primarily on oxygen removal technology as well as management of flexible scrap remelting. Commercialized processes are focused on electrolytic refining of sponge titanium in molten salt and calcium deoxidation. Otherwise, less well sorted or more contaminated (for example, iron-contaminated titanium generated in the smelting process) titanium would be used predominantly within ferro-titanium (Fig. 1; global demand 60,000 tons per year) or as an additive within other metal streams such as steel, nickel, copper or aluminium.

Another fundamental challenge associated with high scrap usage in production is that the properties (such as strength, toughness or corrosion resistance) may vary intolerably between two different furnace charges.Scrap-dependent heat treatment adjustment and the required blending with primarymaterial couldbepredicted using through-process computational materials engineering simulations that must be based on robust phase diagrams and kinetic databases. The customers primarily require specific properties rather than compositions, that is, it may be possible to correct composition-dependent property variations through adjusted, flexible and batch-specific downstream heat treatments, an area where data-driven methods might become helpful.

\section{Sustainable alloy design and recycling-friendly materials}

Progress and opportunities in recycling have focused on achieving an optimal fit of the collected and sorted scraps to existing alloys. Here we approach the task from a different perspective, namely, how the design of metallic alloys could be changed to render them more recyclingoriented upfront. This term refers to the capability of an alloy to be made from the highest possible fractions of (low-grade) scraps and at the same time to be compatible with other alloys when serving as scrap. This means that the elusive goal in optimized materials recovery is not only to understand better the influence of impurity elements on properties, but also to build recyclability directly into the design of materials. Current structural alloys are not devised for end-of-life but rather for one-time use. Research into developing a science of less-pure 
and thus recycling-friendly alloys covers many aspects: small concentration thermodynamics and kinetics; impurity trapping at lattice defects; compositional existence ranges of phases; size, dispersion and composition of harmful intermetallic precipitates; solute-driven cohesion and decohesion effects and associated property changes. Optimization methods coupled with metallurgical design can suggest alloys whose compositional constraints can be modified towards more scrap-tolerant ranges while preserving performance ${ }^{39}$.

This approach marks a shift in alloy design, which currently aims in part at realizing new properties through changes in chemical composition. However, scrap compatibility in secondary production can be better realized when avoiding compositionally over-designed alloys and instead using materials from only a limited composition spectrum, where property tuning is achieved through microstructure adjustment. The best examples are steels, which provide hundreds of material variants with different microstructures and properties, yet all based essentially on the iron-carbon-manganese-silicon (Fe-C-Mn-Si) system.

When taking a closer look at the quest for recycling-friendly alloys, the two approaches (composition tuning and microstructure tuning) are not so different: while the approach of using only limited chemical variation holds, repeated processing of scraps leads to accumulation of contaminants in secondary synthesis. This turns simple alloy systems such as Al-Mg-Si (used, for instance, in automotive sheet production) into a multi-component ${ }^{47}$ material containing also iron, manganese, chromium, titanium, zinc and copper. Some of these impurities can lead to brittle phases. This means that recycling-oriented alloy design must study the low-dose corners of multi-component phase diagrams that may take into account up to twenty elements. A better understanding of multi-component thermodynamics and kinetics is thus an important pillar of the design of more impurity-tolerant alloys ${ }^{48}$.

A related, but more disruptive, scrap-friendly alloy design approach consists in the design of crossover alloys, which are sometimes also referred to as broadband alloys or uni-alloys ${ }^{49}$. This approach aims to replace the variety of over-designed alloys by a smaller number of materials each covering a broader range of properties to serve mass markets. For aluminium, where 250 specialized alloys are stocked but only 65 are regularly used, such crossover alloys could combine features of heattreatable and non-heat-treatable wrought alloys at broad composition tolerance and with wide application ranges, establishing a universal alloy concept. A specific example is the improvement of the strain-hardening capacity, which is needed in sheet forming. This can be achieved both by a higher solute magnesium content, owing to its effect on dislocation motion, but also by tuning crystallographic texture, reducing grain and dislocation cell sizes and improving precipitate dispersion.

Similar aspects apply to Al-Mn alloys, used in recycling-intensive branches such as packaging, which for non-safety-critical products can tolerate a large variation in composition (the impurity concentration of some contaminants such as iron, silicon, zinc and magnesium can vary by factors of up to five among batches; Fig. 3).

\section{Longevity by corrosion protection, lifetime extension and re- use}

Enabling longer-lasting products would reduce resource extraction through lifetime extension and repairability of products or by facilitating re-use (Fig. 2$)^{13}$. We note, however, that increasing product lifetime will not reduce the demand arising from increasing population. Therefore, for developing regions where the population is growing this strategy is of limited value. The longevity of alloys is mainly limited by fatigue, creep, corrosion including hydrogen embrittlement, thermal ageing and irradiation.

Fatigue is an effect of permanent microplastic deformation when a material is exposed to cyclic loading. This often occurs together with thermal and/or corrosive attack owing to the presence of oxygen and hydrogen, causing a phenomenon known as stress corrosion cracking. A similar scenario of gradual material decay is caused by creep, which is a phenomenon where thermal activation enables plastic flow and microstructure coarsening of parts exposed to high homologous temperatures.

Corrosion and stress-corrosion cracking are by far the most severe phenomena limiting the longevity and integrity of metal products, destroying about $3.4 \%$ of the global gross domestic product every year, a value translating to US $\$ 2.5$ trillion (ref. ${ }^{50}$ ) (see Fig. 2 ). Hence, any progress in corrosion resistance has large effects on longevity, most relevant for carbon steel.

In this context, loss of material and system failure due to oxidation accounts for the vast majority of the economic impact of corrosion and is an essential factor in infrastructure costs worldwide. Oxidation of metallic structures proceeds mostly through galvanic corrosion, which occurs when adjacent microstructural regions or different metals with unlike electrochemical potentials are in conductive contact. The electrochemically more active region then acts as anode and corrodes faster than the cathodic reactant. Galvanic corrosion is the prevalent decay mechanism when metal structures are in contact with an electrolyte such as water with solute ions.

Hydrogen embrittlement is another type of corrosion and poses a serious impediment for carbon-free hydrogen-propelled technologies. Unlike other corrosion products such as oxides and hydroxides, hydrogen is hard to detect and several embrittling effects can occur such as hydrogen-enhanced plasticity, decohesion, superabundant vacancies, hydride formation or nanovoids. The interplay among them makes it difficult to identify a clear cause of failure. Also, hydrogen-related damage can occur suddenly, causing abrupt catastrophic failure of structures. Hydrogen embrittlement can occur in structural alloys ${ }^{51,52}$, particularly in iron, aluminium, nickel and titanium alloys with strength levels above $650 \mathrm{MPa}$.

Alloy lifetime can also be reduced by thermal and radiation effects ${ }^{53,54}$, causing brittle phases, enhanced abundance and mobility of lattice defects or capillary-driven microstructure coarsening ${ }^{55,56}$. The industrial relevance of this is huge. Many components in the energy industry, specifically in nuclear reactors, can suffer from these phenomena, making it a field where safety issues can sometimes override sustainability concerns.

Measures to reduce fatigue and creep damage in alloys use some of the intrinsic damage-resistance and crack closure mechanisms that metals offer ${ }^{57-59}$. Examples are crack closure induced by plastic deformation, chemical reactions such as oxidation or athermal phase transformation $^{60-62}$ which are caused by the stress increase before a crack tip, triggering stress-driven phase transformation. This is often non-volume conserving, thus creating compressive stresses that can close crack tips. Another approach is diffusion-driven pore filling during creep ${ }^{63}$. Since most corrosion phenomena are interface-dominated reactions involving mass transport (mostly of metal and oxygen ions), corrosion protection (particularly against oxidation) is among the most important and efficient means of enhancing product longevity.

Corrosion protection methods are as varied as the underlying reactions and decay phenomena. Methods for mitigating oxidation depend on the underlying electrochemical reactions and the nature of the resulting products (see steel in Fig. 2). Countermeasures may rely on shifting the thermodynamic direction of the oxidation reaction by providing a sacrificial anode, engineering alloy compositions to favour formation of a protective oxide or to disfavour formation of detrimental phases, or directly preventing oxygen from reaching the vulnerable material via protective coatings. (Technological schemes, such as impressed current cathodic protection, are also widely applied but are beyond the scope of this review.)

Steel protection via zinc coatings is the most frequent application of a sacrificial anode against atmospheric oxygen exposure and accounts for half of the global zinc production of 13.5 Mt per year. Hence, environmental considerations apply also to zinc production and recycling when improving the longevity of steels. Some metals, such as many aluminium, titanium, nickel and stainless-steel alloys, form dense, 


\section{Review}

adherent, self-healing oxidation products that resist corrosion intrinsically by preventing further oxygen intrusion. Even in these materials, interfacial segregation and second phase formation can contribute corrosive damage. Finally, engineering protective coatings is an art in itself, since an imperfect or permeable coating can actually enhance the corrosion it is meant to prevent.

Protecting materials against hydrogen is challenging: whereas some materials such as titanium undergo formation of brittle hydrides, others such as nickel and high-strength steels experience enhanced local plasticity and void formation. Measures that may reduce hydrogen embrittlement are the reduction of regions of high micromechanical contrast among phases and microstructure components (as hydrogen tends to enrich in highly stressed regions such as at interfaces), dense oxide surface layers which reduce hydrogen uptake, and trapping of hydrogen at semi-coherent internal interfaces and supposedly also at other defects ${ }^{64-66}$. In some cases, hydrogen trapping can be a cause of undesired local softening, such as through the stabilization of superabundant vacancies or the lowering of the activation barriers for the double-kink mechanism of dislocation motion ${ }^{67,68}$.

When damage becomes visible, repairs can be done by cladding, welding or grinding for components ranging from bridges ${ }^{69,70}$ to turbine blades $^{71,72}$. Repairs can be conducted even when damage is not visible, for example, through maintenance treatments. There has been considerable research on self-healing metals, in which the main goal is that the material should have autonomous crack closure mechanisms ${ }^{73,74}$. Yet ambient temperature sluggishness of transformation kinetics in metals $^{75,76}$ limits the success of a truly autonomous crack closure mechanism to only a few case studies ${ }^{77}$. Most other cases require external treatments. The repairability of metals can be increased by focusing on removing microstructural changes that lead to embrittlement, instead of focusing only on micro-crack closure. This would enable prolonged utilization of intrinsic damage resistance that is intrinsic, but consumable (that is, it is gradually used up) in alloys exposed to repeated mechanical loads, which arise from plasticity ${ }^{62,78}$ or transformation ${ }^{58,79}$ micro-mechanisms. Thermally induced embrittlement effects in duplex stainless steels, which is due to $\mathrm{G}$-phase formation (a $\mathrm{CrNi}$-silicide), can be removed by annealing, enabling the part's re-use ${ }^{80}$. Similarly, cut-edge damage in sheet metal can be reduced by specifically designed cutting treatments ${ }^{81}$. Furthermore, such microstructure resetting strategies could enable further re-manufacturing processes for sheet metal that would increase re-use ${ }^{82}$.

Approaches to improving the sustainability of structural metals are supported by progress in computational methods. Metallurgists can now make use of databases of experimental data surrounding structure-property relationships, loading-specific precipitation, coarsening, phase transformation and even complete-lifetime predictions ${ }^{48,83,84}$. Data-driven approaches can use machine learning methods ${ }^{85-89}$ that can sometimes be computationally more tractable than simulation-based approaches that aim to avoid damage-susceptible microstructures (to reduce failure) ${ }^{90}$ or to make predictions for when to apply repair treatments and how alloy compositions can be rendered more compatible for recycling.

Enabling re-use provides considerable opportunities for steel and aluminium, given that many applications in building and transportation reach end-of-life not because they fail but because they are replaced for economic reasons. Barriers to re-use are typically not technical in nature but rather economic, such as lack of demand, traceability concerns and lack of supply chain infrastructure ${ }^{91}$. These systemic barriers need to be addressed to realize re-use potential through government leadership, education and information sharing.

\section{Energy efficiency by lightweighting and harsh operating conditions}

Metallurgical improvements can increase the performance and energy efficiency of industrial systems, products and processes simultaneously,

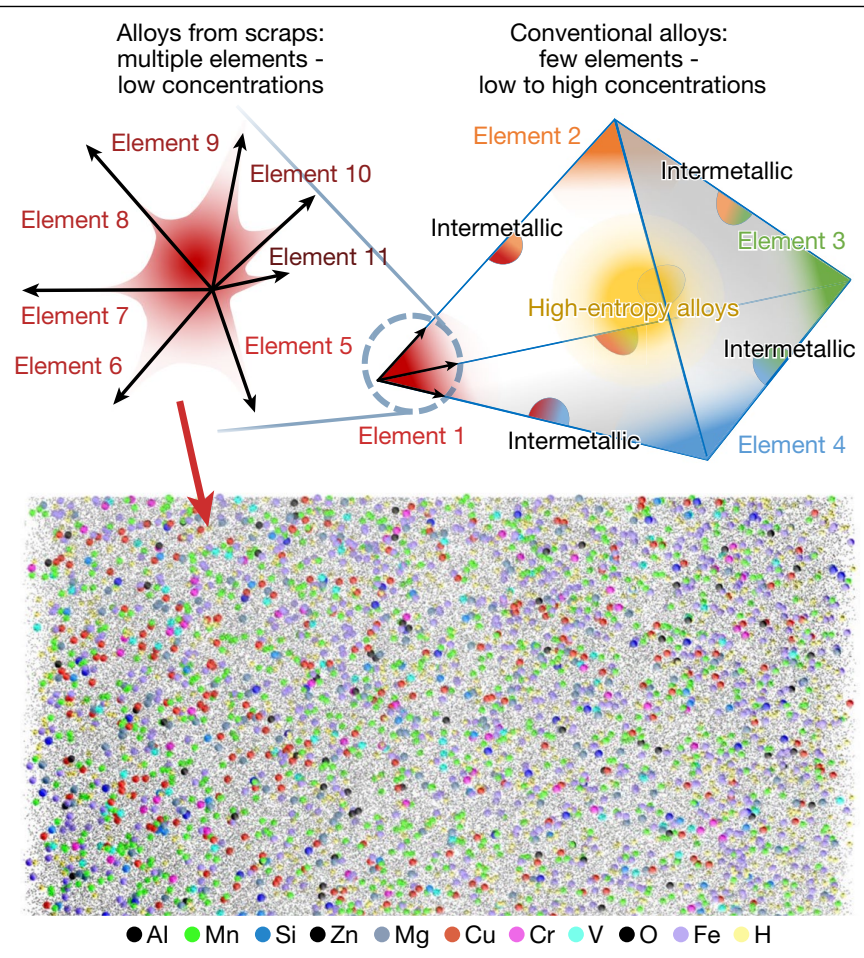

Fig. 3 | Multi-component alloys for high scrap usage. Alloys made from high scrap fractions can contain multiple contaminants, which means that they must be designed initially to be impurity-tolerant. This requires knowledge about low-concentration, multi-component phase diagram regions. The schematic shows a phase diagram with typical engineering alloys in the corners, where one element prevails, and intermetallics in the binary and ternary centres with fixed stoichiometries and high- and medium-entropy alloys as solid-solutions in the centres of the multi-component phase diagrams. The presence of scrap-related contaminants makes this a low-concentration, multi-component phase diagram. Below is an atom probe tomography dataset taken from a recycled Al-Mn base alloy used for packaging, revealing a high number of tolerable impurity elements, each below $0.1 \%$. Such recycled Al-Mn alloys can also serve in infrastructure applications.

at reduced waste and greenhouse gas emissions. Here we tackle two pathways towards increasing 'in-use' energy efficiency: lightweighting (alloy design for weight reduction, Fig. 2) and increased operating temperature (efficiency through high-temperature materials, Fig. 2).

Worldwide, approximately $12 \%$ of steel products (about 121 Mt per year) and about $27 \%$ of aluminium products ( $12 \mathrm{Mt}$ per year) are used in transportation, incentivizing efforts to reduce weight in automotive ${ }^{92-95}$, aerospace ${ }^{96-98}$ and railway ${ }^{99}$ components. In the case of vehicle lightweighting, the potential is considerablegiven that $20 \%$ of our global energy and process $\mathrm{CO}_{2}$ emissions originate from transportation and about $20 \%$ of that could be reduced through lightweighting ${ }^{100}$. We note that, historically, vehicles have become heavier over time with improvements to comfort, performance and safety, even as our ability to lightweight the vehicle has improved. Lightweighting has sustainability benefits for other industries linked with transportation as well, such as the packaging (about $9 \mathrm{Mt}$ per year of steel, about $6 \mathrm{Mt}$ per year of aluminium) or construction industries (583 Mt per year of steel, $11 \mathrm{Mt}$ per year of aluminium) (see Fig. 1). Efforts to reduce materials use through redesign, including alloy development and particularly microstructure tuning, could remove as much as $30 \%$ of steel and aluminium by mass from transportation uses.

In each of these industries, weight can be reduced (1) by using less metal, compensated by higher strength, (2) by using metal of lower density, or (3) by optimizing component design.(1) Using less metal means improved strength or elastic modulus properties must be achieved, while avoiding a decrease in toughness and ductility. There are several strengthening mechanisms that can be triggered in metals by optimizing 
thermo-mechanical processing and/or composition, but many of them reduce ductility and toughness. Therefore, designing metals that exhibit simultaneous increases in these properties has been an essential goal of metallurgical research ${ }^{2,101-104}$. The most effective mechanisms for improving strength and ductility simultaneously have been by phase metastability. Transformation-induced plasticity (TRIP) and twinninginduced plasticity (TWIP) mechanisms have been extensively used for this purpose, in TRIP-assisted ${ }^{93,105-107}$ or TWIP-assisted ${ }^{108-110}$ steels and titanium alloys ${ }^{111,112}$ through 'metastability' tuning of the stacking fault energy, achieved mainly by adjusting the carbon and manganese content and composition partitioning among phases. A more fundamental challenge is regarding the end product of strain-induced martensitic transformation: martensite. Although its transformation reaction has beneficial effects, the resulting fresh martensite and its bounding hetero-interfaces are often sites of damage nucleation ${ }^{94}$. Similarly, the elastic modulus is an essential design consideration for vehicle mass reduction. Several high-stiffness metal matrix composites have been developed using stiff ceramic precipitates. Examples are $\mathrm{Al}-\mathrm{TiB}_{2}$ and $\mathrm{Fe}-\mathrm{TiB}_{2}$. Some of these materials provide improved stiffness of up to $10 \%$ with comparable formability. Upscaling depends on the capability to produce such alloys in larger quantities, for example, through in situ liquid metallurgy ${ }^{113}$.

(2) For the second approach to lightweighting, one goal is reducing the density of steels. When blending Fe with up to $25 \%$ manganese and up to $1.2 \%$ carbon the steel crystallizes into a face-centred-cubic structure, tolerating up to 8 atomic per cent aluminium in solid solution without formation of brittle phases. These materials are referred to as low-density steels and have a tensile strength up to $1.5 \mathrm{GPa}$ at up to $60 \%$ elongation. When adding 20 atomic per cent $\mathrm{Al}$ to $\mathrm{Fe}-\mathrm{Mn}-\mathrm{C}$ alloys the mass density is reduced by as much as $15 \%$, yet with reduced Young's modulus and precipitation of perovskitic carbides ${ }^{3}$.

Another avenue for weight reduction makes use of aluminiumbased $^{4,114}$ and magnesium-based ${ }^{1,115}$ alloys. Current research is focused on achieving a better strength-ductility compromise for sheet applications, realizing ultrahigh-strength $\mathrm{Al}-\mathrm{Zn}-\mathrm{Mg}-\mathrm{Cu}^{116}$, as well as weightreduced and stiffness-enhanced $\mathrm{Al}-\mathrm{Li}$ alloys ${ }^{117}$. Several even lighter alloys are currently being developed, based on the $\mathrm{Mg}-\mathrm{Al}-\mathrm{Zn}^{115}, \mathrm{Mg}$ $\mathrm{Al}-\mathrm{Ca}^{118,119}$ and Mg-rare-earth ${ }^{120}$ systems, with a mass density as low as about $1.7 \mathrm{~g} \mathrm{~cm}^{-3}$, that is, about $80 \%$ reduced density compared to steels. Extreme weight reduction, but with insufficient corrosion resistance was realized in a Mg-Li alloy that approaches a mass density of only about $1 \mathrm{~g} \mathrm{~cm}^{-3}$ (that is, that of water ${ }^{121}$ ).

(3) Design improvements can also lead to weight reductions. Here, our focus is not on topology optimization ${ }^{122}$, but on mesoscale optimization of the spatial distribution of microstructure features ${ }^{123}$. In cases where processing is feasible, grading of structure or composition can enhance properties ${ }^{124-127}$, enabling lightweighting. Materials designers have explored gradients of grain size ${ }^{124,127-129}$, twin density ${ }^{130,131}$, component or phase fraction ${ }^{132}$. These investigations demonstrated that the underlying physical micro-mechanisms of deformation can be influenced by such grading, leading to improvements in plasticity $^{133,134}$, strengthening ${ }^{135}$, and damage resistance ${ }^{124,127,130,131,136}$. However, processes that realize gradients are difficult to scale up (for example, accumulative roll bonding ${ }^{137,138}$, thin film deposition ${ }^{139,140}$ ). To this end, additive manufacturing methods offer potential for the synthesis of graded materials, and can be also employed to create functionally graded structures ${ }^{141-146}$, although costs and production speed need to be improved.

Another field of interest is the overlap between additive manufacturing, alloy design, architectured materials, computational materials mechanics and bionics. Bionic design enables computer-generated topology-optimized lean geometries of parts at reduced mass and improved structural stiffness ${ }^{122,147}$ (Fig. 4).

Another domain where structural alloys offer improved efficiency is the use of higher operational temperatures in energy conversion ${ }^{5,6}$.

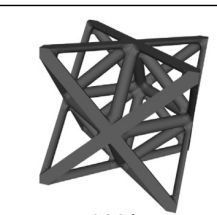

$10 \%$

Cellular density

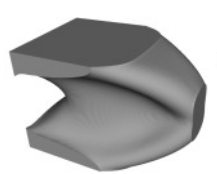

$0.6 \mathrm{VF}+10 \% \mathrm{CD}$

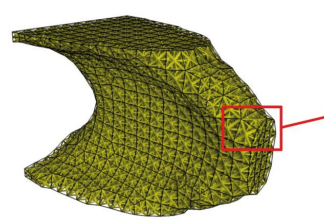

$0.3 \mathrm{VF}+20 \% \mathrm{CD}$

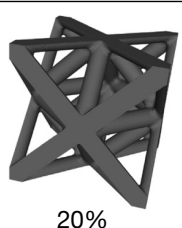

$20 \%$

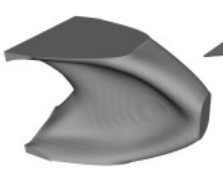

$0.3 \mathrm{VF}+20 \% \mathrm{CD}$
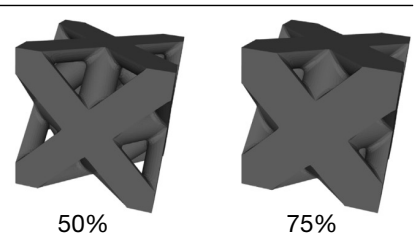

$75 \%$

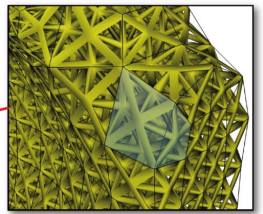

$0.3 \mathrm{VF}+20 \% \mathrm{CD}$
$0.3 \mathrm{VF}+20 \% \mathrm{CD}$ as printed

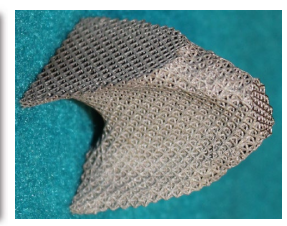

Fig. 4 | Synergies between structural optimization, additive manufacturing, architectured materials and bionics. Example of a three-dimensional cantilever beam design using these synergies. The upper row shows an architectured lattice structure with different cellular densities (CD) ranging from $10 \%$ to $75 \%$. The middle row shows different combinations of volume fraction (VF) and CD for a part obtained by topology optimization. The four combinations all yield the same reduction in weight (94\%) relative to the massive (un-architectured, not porous) cantilever beam with $100 \% \mathrm{VF}$ and $100 \% \mathrm{CD}$. The image was compiled using results from ref. ${ }^{147}$.

Such engines follow the Carnot cycle, and hence higher service temperatures yield better efficiency. As global electricity consumption amounts to $23 \mathrm{PW} \mathrm{h}\left(10^{15} \mathrm{~W}\right.$ h) and electricity is the fastest-growing source of energy demand, most of it provided by turbines, higher conversion efficiency has huge potential for saving energy. This should stimulate research on nickel-based and cobalt-based superalloys, Tialuminides and Mo-Si-B alloys (Fig. 2).

\section{Outlook on enhanced sustainability of structural metals}

Structural metallic alloys have served as key enablers of human progress, wealth and wellbeing over millennia. Now, in the acceleration phase of the Anthropocene, their great advantages in terms of availability, mass producibility and low price have also become an environmental burden. Considering the huge quantities produced (1.7 billion tons of steel and 94 million tons of aluminium per year), the task of making structural alloys and their products sustainable is an enormous challenge. Metals-related sustainability solutions now require a holistic view of production and manufacturing, and a thorough metallurgical understanding of structure-property relations, product function and longevity, resource efficiency, pollution, market dynamics and societal impact $^{12}$. These aspects are closely connected, with some of them being of thermodynamic nature (and therefore quantifiable), whereas others are harder to assess, such as customer response to green branding or market development ${ }^{148}$. We therefore recommend the use of marketinformed life-cycle assessment calculations for adequate risk and effect quantification before political and industrial decision-making, in order to reveal the true long-term efficiency gains of the various possible sustainability measures.

To improve the sustainability of metals production and use, several recommendations with both high leverage and high technologyreadiness follow from this overview. The greatest potential is attributed to the use of fossil-free and fossil-reduced energy sources in primary and secondary extraction and manufacturing as well as production methods that allow the dynamic use of green electricity. Also of great 


\section{Review}

importance are improved corrosion resistance; materials-efficient manufacturing; improved product-to-product recycling; automated post-consumer scrap sorting; recycling-oriented alloy design and the development of multi-purpose crossover alloys.

Acritical dimension in realizing many of the opportunities mentioned here that we have left untouched in our discussion is the importance of government action and economics. In the absence of regulations, the only driving force for emission reductions would be those strategies that can demonstrate economic benefit. The role of policy would be to leverage quantitative assessments to incentivize the most effective (in terms of sustainability) strategies ${ }^{19}$. Several current metal-industryrelated policies are inadequate, focusing on technology-specific deployment substitutes, or are not sufficiently transformative, therefore leaving potential for lock-in risk ${ }^{149}$. Measures that deserve immediate attention include pollution and emission controls across national borders, demand stimuli such as procurement mandates or recycling incentives that consider both sources and sinks for recovered metal, and supply measures that are technology-neutral but set benchmarks and standards for clean manufacturing while supporting scale-up needs, all coupled to supporting infrastructure and market analysis to enable the most economically viable strategies compatible with these sustainability goals ${ }^{152}$.

Systematically implementing the measures discussed will break with almost all traditions of our current industrial practice since the beginning of the first industrial revolution around 1800. Striving towards sustainability will become the next industrial revolution.

1. Pollock, T. M. Weight loss with magnesium alloys. Science 328, 986-987 (2010). This milestone paper provides an overview of how to reach lightweight, energyefficient, environmentally benign engineering systems using magnesium alloys.

2. Jiang, S. et al. Ultrastrong steel via minimal lattice misfit and high-density nanoprecipitation. Nature 544, 460-464 (2017).

3. Raabe, D. et al. Alloy design, combinatorial synthesis, and microstructure-property relations for low-density Fe-Mn-Al-C austenitic steels. JOM 66, 1845-1856 (2014) This is an overview of aluminium-containing, high-manganese steels that are characterized by an excellent combination of strength and ductility, enabled by their high work hardening capacity.

4. Hirsch, J. Aluminium in innovative light-weight car design. Mater. Trans. 52, 818-824 (2011)

5. Reed, R. C. The Superalloys (Cambridge Univ. Press, 2009)

6. Pollock, T. M. \& Tin, S. Nickel-based superalloys for advanced turbine engines: chemistry, microstructure and properties. J. Propuls. Power 22, 361-374 (2006).

7. Bloom, E. E. The challenge of developing structural materials for fusion power systems. J. Nucl. Mater. 258-263, 7-17 (1998)

8. Witte, F. et al. Degradable biomaterials based on magnesium corrosion. Curr. Opin. Solid State Mater Sci. 12, 63-72 (2008).

9. Luo, H., Li, Z. \& Raabe, D. Hydrogen enhances strength and ductility of an equiatomic high-entropy alloy. Sci. Rep. 7, 9892 (2017).

10. Dunn, B. D. Materials and Processes for Spacecraft and High Reliability Applications. (Springer, 2016)

11. Optimat Materials Landscaping Study. Report J2963/IUK (Optimat, 2018)

12. World Economic Forum Mining \& Metals in a Sustainable World 2050. Scoping Report (World Economic Forum, 2015)

13. Allwood, J. M. \& Cullen, J. M. Sustainable Materials: With Both Eyes Open (UIT Cambridge 2012)

This seminal book is a very detailed and holistic treatment of all engineering and commercial issues related to materials sustainability with special attention paid to the required reduction of the industry's carbon emissions by $50 \%$ by 2050

14. Graedel, T. E. et al. What do we know about metal recycling rates? J. Ind. Ecol. 15, 355-366 (2011).

15. Ferretti, I., Zanoni, S., Zavanella, L. \& Diana, A. Greening the aluminium supply chain Int. J. Prod. Econ. 108, 236-245 (2007)

16. Mahfoud, M. \& Emadi, D. Aluminum recycling-challenges and opportunities. Adv. Mater Res. 83-86, 571-578 (2009).

17. Strezov, V., Evans, A. \& Evans, T. Defining sustainability indicators of iron and steel production J. Clean Prod .51, 66-70 (2013).

18. Allanore, A., Yin, L. \& Sadoway, D. R. A new anode material for oxygen evolution in molten oxide electrolysis. Nature 497, 353-356 (2013)

19. Fischedick, M., Marzinkowski, J., Winzer, P. \& Weigel, M. Techno-economic evaluation of innovative steel production technologies. J. Clean. Prod. 84, 563-580 (2014).

20. Sastri, M. V. C., Viswanath, R. P. \& Viswanathan, B. Studies on the reduction of iron oxide with hydrogen. Int. J. Hydrogen Energy 7, 951-955 (1982).

21. Chu, M., Nogami, H. \& Yagi, J. Numerical analysis on injection of hydrogen bearing materials into blast furnace. ISIJ Int. 44, 801-808 (2004).

22. Muramatsu, A., Sato, H., Akiyama, T. \& Yagi, J. Methanol synthesis from blast furnace off gas. ISIJ Int. 33, 1144-1149 (1993)
23. Gielen, D. $\mathrm{CO}_{2}$ removal in the iron and steel industry. Energy Convers. Manage. $\mathbf{4 4}$ 1027-1037 (2003).

24. Battle, T., Srivastava, U., Kopfle, J., Hunter, R. \& McClelland, J. The direct reduction of iron. In Treatise on Process Metallurgy Vol. 3 (ed. Seetharaman, S.) 89-176 (2014)

25. Vogl, V., Åhman, M. \& Nilsson, L. J. Assessment of hydrogen direct reduction for fossil-free steelmaking. J. Clean. Prod. 203, 736-745 (2018).

This book provides a detailed analysis of the feasibility and costs associated with the use of hydrogen as a reducing agent in the direct reduction of iron ores and the resulting opportunities to turn carbon-based iron production into a hydrogen- and electricity-based one.

26. Gusberti, V., Severo, D. S., Welch, B. J. \& Skyllas-Kazacos, M. Modeling the mass and energy balance of different aluminium smelting cell technologies. In Light Metals 2012 (ed. Suarez, C. E.) 929-934 (2016).

27. Olivetti, E. A. \& Cullen, J. M. Toward a sustainable materials system. Science $\mathbf{3 6 0}$ 1396-1398 (2018).

This paper discusses how materials extraction has shifted from Europe and North America to Asia and Africa.

28. Allwood, J. M., Cullen, J. M. \& Milford, R. L. Options for achieving a $50 \%$ cut in industrial carbon emissions by 2050. Environ. Sci. Technol. 44, 1888-1894 (2010).

29. Azevedo, J. M. C. Cabrera Serrenho, A. \& Allwood, J. M. Energy and material efficiency of steel powder metallurgy. Powder Technol. 328, 329-336 (2018).

30. Raabe, D. Microstructure and crystallographic texture of strip-cast and hot-rolled austenitic stainless steel. Metall. Mater. Trans. A 26, 991-998 (1995).

31. Raabe, D., Reher, F., Hölscher, M. \& Lücke, K. Textures of strip cast Fe16\%Cr. Scr. Metall. Mater. 29, 113-116 (1993).

32. Haga, T., Nishiyama, T. \& Suzuki, S. Strip casting of A5182 alloy using a melt drag twin-roll caster. J. Mater. Process. Technol. 133, 103-107 (2003).

33. Monaghan, D. J., Henderson, M. B., Hunt, J. D. \& Edmonds, D. V. Microstructural defects in high productivity twin-roll casting of aluminium. Mater. Sci. Eng. A 173, 251-254 (1993).

34. Zink, T., Geyer, R. \& Startz, R. A market-based framework for quantifying displaced production from recycling or reuse. J. Ind. Ecol. 20, 719-729 (2016).

35. Rombach, G. Raw material supply by aluminium recycling-efficiency evaluation and longterm availability. Acta Mater. 61, 1012-1020 (2013).

This work provides a detailed analysis and discussion of scrap cycles, scrap markets and associated secondary production opportunities for the case of aluminium alloys.

36. Brooks, L., Gaustad, G., Gesing, A., Mortvedt, T. \& Freire, F. Ferrous and non-ferrous recycling: challenges and potential technology solutions. Waste Manag. 85, 519-528 (2019)

This review article provides detail regarding inbound inspection for metals recycling at a level of detail that enables action by industry and decision makers.

37. Rombach, G. \& Bauerschlag, N. LIBS-based sorting-a solution for automotive scrap. In Light Metal 2019 (ed. Chesonis, C.) 1351-1357 (2019).

38. Gaustad, G., Olivetti, E. A. Kirchain, R. Improving aluminum recycling: a survey of sorting and impurity removal technologies. Resour. Conserv. Recycling 58, 79-87 (2012)

This paper carefully analyses the undesired accumulation of tramp elements during the recycling of aluminium alloys.

39. Modaresi, R., Løvik, A. N. \& Müller, D. B. Component- and alloy-specific modeling for evaluating aluminum recycling strategies for vehicles. JOM 66, 2262-2271 (2014)

This study discusses alloy design challenges and solution approaches to make better recycling use of mixed shredded aluminium scrap from end-of-life vehicles.

40. Enkvist, P. A. Klevnas, P. The Circular Economy-A Powerful Force for Climate Mitigation. (Material Economics Sverige, 2018)

41. Haupt, M., Vadenbo, C., Zeltner, C. \& Hellweg, S. Influence of input-scrap quality on the environmental impact of secondary steel production. J. Ind. Ecol. 21, 391-401 (2017)

42. Daehn, K. E., Cabrera Serrenho, A. \& Allwood, J. M. How will copper contamination constrain future global steel recycling? Environ. Sci. Technol. 51, 6599-6606 (2017).

This paper focuses on copper contamination in steel through a detailed characterization of copper in the global steel system along the steel supply chain to quantify the maximum concentration of copper in steel products.

43. Elshkaki, A., Reck, B. K. \& Graedel, T. E. Anthropogenic nickel supply, demand, and associated energy and water use. Resour. Conserv. Recycling 125, 300-307 (2017).

44. Reck, B. K. \& Rotter, V. S. Comparing growth rates of nickel and stainless steel use in the early 2000s. J. Ind. Ecol. 16, 518-528 (2012).

45. Worrell, E. \& Reuter, M. A. Handbook of Recycling: State-of-the-art for Practitioners, Analysts, and Scientists (Elsevier, 2014)

This is a comprehensive presentation of materials recovery that provides insight into recycling technologies, economics, and policy for a comprehensive set of materials, focusing on steel, copper and nickel (in the context of stainless steel).

46. Takeda, O. \& Okabe, T. H. Current status of titanium recycling and related technologies. JOM 71, 1981-1990 (2019).

47. Pogatscher, S. et al. Statistical and thermodynamic optimization of trace-element modified Al-Mg-Si-Cu alloys. In Light Metals 2015 (ed. Hyland, M.) 263-270 (2015)

48. Liu, Z.-K. \& Wang, Y. Computational Thermodynamics of Materials (Cambridge Univ. Press, 2016).

49. Ebenberger, P. et al. Processing-controlled suppression of Lüders elongation in AlMgMn alloys. Scr. Mater. 166, 64-67 (2019).

50. Koch, G. H., Brongers, M. P. H., Thompson, N. G., Virmani, Y. P. \& Payer, J. H. Corrosion Costs and Preventive Strategies in the United States. Technical report 200224 (Federa Highway Administration, 2002).

51. Song, R. G. et al. Stress corrosion cracking and hydrogen embrittlement of an Al-Zn-MgCu alloy. Acta Mater. 52, 4727-4743 (2004). 
52. Martin, M. L., Dadfarnia, M., Nagao, A., Wang, S. \& Sofronis, P. Enumeration of the hydrogen-enhanced localized plasticity mechanism for hydrogen embrittlement in structural materials. Acta Mater. 165, 734-750 (2019).

This is an overview of experiments and simulation results about the hydrogenenhanced localized plasticity (HELP) mechanism as a viable hydrogen embrittlement mechanism in structural materials for a hydrogen economy.

53. Odette, G. R., Alinger, M. J. \& Wirth, B. D. Recent developments in irradiation-resistant steels. Annu. Rev. Mater. Res. 38, 471-503 (2008).

54. Zinkle, S. J. \& Busby, J. T. Structural materials for fission \& fusion energy. Mater. Today 12, 12-19 (2009).

55. Yao, Y., Wei, J., Liu, J., Wang, Z. \& Wang, Y. Thermal ageing embrittlement of casting duplex stainless steels for nuclear power plant. In 18th Int. Conf. on Nuclear Engineering Vol. 5, 625-630 (2011).

56. Li, S., Wang, Y. \& Wang, X. Effects of ferrite content on the mechanical properties of thermal aged duplex stainless steels. Mater. Sci. Eng. A 625, 186-193 (2015).

57. Ritchie, R. O. Mechanisms of fatigue crack propagation in metals, ceramics and composites: role of crack tip shielding. Mater. Sci. Eng. 103, 15-28 (1988).

58. Koyama, M. et al. Bone-like crack resistance in hierarchical metastable nanolaminate steels. Science 355, 1055-1057 (2017).

59. Dai, K. \& Shaw, L. Analysis of fatigue resistance improvements via surface severe plastic deformation. Int. J. Fatigue 30, 1398-1408 (2008)

60. Baxevanis, T., Parrinello, A. F. \& Lagoudas, D. C. On the fracture toughness enhancement due to stress-induced phase transformation in shape memory alloys. Int. J. Plast. 50 158-169 (2013).

61. Pippan, R. \& Hohenwarter, A. Fatigue crack closure: a review of the physical phenomena Fatigue Fract. Eng. Mater. Struct. 40, 471-495 (2017).

62. Ritchie, R. O. Mechanisms of fatigue-crack propagation in ductile and brittle solids. Int. J. Fract. 100, 55-83 (1999).

63. Zhang, S. et al. Autonomous filling of grain-boundary cavities during creep loading in Fe-Mo alloys. Metall. Mater. Trans. A 47, 4831-4844 (2016).

64. Takahashi, J., Kawakami, K., Kobayashi, Y. \& Tarui, T. The first direct observation of hydrogen trapping sites in $\mathrm{TiC}$ precipitation-hardening steel through atom probe tomography. Scr. Mater. 63, 261-264 (2010).

65. Chen, Y. S. et al. Direct observation of individual hydrogen atoms at trapping sites in a ferritic steel. Science 355, 1196-1199 (2017).

66. Chang, Y. et al. Quantification of solute deuterium in titanium deuteride by atom probe tomography with both laser pulsing and high-voltage pulsing: influence of the surface electric field. New J. Phys. 21, 053025 (2019).

67. Kirchheim, R. Solid solutions of hydrogen in complex materials. In Solid State Phys Vol. 59 (eds Ehrenreich, H. \& Spaepen, F.) 203-291 (2004).

68. Pundt, A. \& Kirchheim, R. Hydrogen in metals: microstructural aspects. Annu. Rev. Mater. Res. 36, 555-608 (2006)

69. Nozaka, K., Shield, C. K. \& Hajjar, J. F. Effective bond length of carbon-fiber-reinforced polymer strips bonded to fatigued steel bridge I-girders. J. Bridge Eng. 10, 195-205 (2005).

70. Garlock, M., Paya-Zaforteza, I., Kodur, V. \& Gu, L. Fire hazard in bridges: review, assessment and repair strategies. Eng. Struct. 35, 89-98 (2012).

71. Yilmaz, O., Gindy, N. \& Gao, J. A repair and overhaul methodology for aeroengine components. Robot. Comput.-Integr. Manuf. 26, 190-201 (2010).

72. Mokadem, S., Bezençon, C., Hauert, A., Jacot, A. \& Kurz, W. Laser repair of superalloy single crystals with varying substrate orientations. Metall. Mater. Trans. A 38, 1500-1510 (2007).

73. Grabowski, B. \& Tasan, C. C. Self-healing metals. Adv. Polym. Sci. 273, 387-407 (2016).

74. Hager, M. D., Greil, P., Leyens, C., Van Der Zwaag, S. \& Schubert, U. S. Self-healing materials. Adv. Mater. 22, 5424-5430 (2010).

75. Hautakangas, S., Schut, H., van der Zwaag, S. \& van Dijk, N. H. The role of the aging temperature on the self-healing kinetics in an underaged $\mathrm{Aa} 2 \mathrm{O} 24$ aluminium alloy. Proc. 1st Int. Conf. on Self Healing Materials 1-7 (2007).

76. He, S. M., Van Dijk, N. H., Schut, H., Peekstok, E. R. \& Van Der Zwaag, S. Thermally activated precipitation at deformation-induced defects in Fe-Cu and Fe-Cu-B-N alloys studied by positron annihilation spectroscopy. Phys. Rev. B 81, 094103 (2010).

77. Zhang, S. et al. Autonomous repair mechanism of creep damage in Fe-Au and Fe-Au-B-N alloys. Metall. Mater. Trans. A 46, 5656-5670 (2015).

78. Hoefnagels, J. P. M., Tasan, C. C., Maresca, F., Peters, F. J. \& Kouznetsova, V. G. Retardation of plastic instability via damage-enabled microstrain delocalization. J. Mater. Sci. 50, 6882-6897 (2015).

79. Mei, Z. \& Morris, J. W. Analysis of transformation-induced crack closure. Eng. Fract. Mech 39, 569-573 (1991)

80. Li, S. L. et al. Annealing induced recovery of long-term thermal aging embrittlement in a duplex stainless steel. Mater. Sci. Eng. A 564, 85-91 (2013).

81. Hoefnagels, J. P. M., Du, C. \& Tasan, C. C. Laser-induced toughening inhibits cut-edge failure in multi-phase steel. Scr. Mater. (in the press).

82. Cooper, D. R. \& Allwood, J. M. Reusing steel and aluminum components at end of product life. Environ. Sci. Technol. 46, 10334-10340 (2012).

83. Roters, F. et al. DAMASK - The Düsseldorf Advanced Material Simulation Kit for modeling multi-physics crystal plasticity, thermal, and damage phenomena from the single crystal up to the component scale. Comput. Mater. Sci. 158, 420-478 (2019).

84. Andersson, J. O., Helander, T., Höglund, L., Shi, P. \& Sundman, B. Thermo-Calc \& DICTRA computational tools for materials science. Calphad 26, 273-312 (2002).

85. Kalidindi, S. R. Hierarchical Materials Informatics (Butterworth-Heinemann, 2015).

86. Kalidindi, S. R. Materials, data, and informatics. In Hierarchical Materials Informatics 1-32 (Butterworth-Heineman, 2015).

87. Kim, E. et al. Materials synthesis insights from scientific literature via text extraction and machine learning. Chem. Mater. 29, 9436-9444 (2017).

88. Kim, E., Huang, K., Jegelka, S. \& Olivetti, E. A. Virtual screening of inorganic materials synthesis parameters with deep learning. npj Comput. Mater. 3, 53 (2017).
89. Ward, L., Agrawal, A., Choudhary, A. \& Wolverton, C. A general-purpose machine learning framework for predicting properties of inorganic materials. npj Comput. Mater. 2, 16028 (2016).

90. Cameron, B. C. \& Tasan, C. C. Microstructural damage sensitivity prediction using spatial statistics. Sci. Rep. 9, 2774 (2019).

91. Densley Tingley, D., Cooper, S. \& Cullen, J. Understanding and overcoming the barriers to structural steel reuse, a UK perspective. J. Clean. Prod. 148, 642-652 (2017).

92. Edmonds, D. V. et al. Quenching and partitioning martensite: a novel steel heat treatment. Mater. Sci. Eng. A 438-440, 25-34 (2006).

93. Grässel, O., Krüger, L., Frommeyer, G. \& Meyer, L. W. High strength Fe-Mn-(Al, Si) TRIP/TWIP steels development-properties-application. Int. J. Plast. 16, 1391-1409 (2000).

The work introduced one of the clearest examples of how transformation induced plasticity (TRIP) or twinning induced plasticity (TWIP) effects can improve property combinations towards reducing the density and increasing the strength of steels.

94. Tasan, C. C. et al. An overview of dual-phase steels: advances in microstructureoriented processing and micromechanically guided design. Annu. Rev. Mater. Res. 45, 391-431 (2015).

95. Galán, J., Samek, L., Verleysen, P., Verbeken, K. \& Houbaert, Y. Advanced high strength steels for automotive industry. Rev. Metal. 48, 118-131 (2012).

96. Heinz, A. et al. Recent development in aluminium alloys for aerospace applications. Mater. Sci. Eng. A 280, 102-107 (2000)

97. Williams, J. C. \& Starke, E. A. Progress in structural materials for aerospace systems. Acta Mater. 51, 5775-5799 (2003).

98. Boyer, R. R. An overview on the use of titanium in the aerospace industry. Mater. Sci. Eng. A 213, 103-114 (1996)

99. Lee, W. G., Kim, J. S., Sun, S. J. \& Lim, J. Y. The next generation material for lightweight railway car body structures: magnesium alloys. Proc. Inst. Mech. Eng. F 232, 25-42 (2018).

100. Helms, H. \& Lambrecht, U. The potential contribution of light-weighting to reduce transport energy consumption. Int. J. Life Cycle Assess. 12, 58-64 (2007).

101. Kim, S.-H., Kim, H. \& Kim, N. J. Brittle intermetallic compound makes ultrastrong lowdensity steel with large ductility. Nature 518, 77-79 (2015).

102. Li, Z., Pradeep, K. G., Deng, Y., Raabe, D. \& Tasan, C. C. Metastable high-entropy dualphase alloys overcome the strength-ductility trade-off. Nature 534, 227-230 (2016).

103. Lei, Z. et al. Enhanced strength and ductility in a high-entropy alloy via ordered oxygen complexes. Nature 563, 546-550 (2018).

104. Wang, Y., Chen, M., Zhou, F. \& Ma, E. High tensile ductility in a nanostructured metal. Nature 419, 912-915 (2002).

105. Matlock, D. K. \& Speer, J. G. Third generation of AHSS: microstructure design concepts. In Microstructure and Texture in Steels (eds Haldar, A. Suwas, S. \& Bhattacharjee, D.) 185-205 (2009).

The work takes an overview of the increased interest in the development of thirdgeneration advanced high-strength steels.

106. Wang, M. M., Tasan, C. C., Ponge, D., Dippel, A. C. \& Raabe, D. Nanolaminate transformation-induced plasticity-twinning-induced plasticity steel with dynamic strain partitioning and enhanced damage resistance. Acta Mater. 85, 216-228 (2015).

107. Fischer, F. D. et al. New view on transformation induced plasticity (TRIP). Int. J. Plast. 16, 723-748 (2000)

108. Steinmetz, D. R., Ja, T., Wietbrock, B. \& Eisenlohr, P. Revealing the strain-hardening behavior of twinning-induced plasticity steels: theory, simulations, experiments. Acta. Mater. 61, 494-510 (2013).

109. Chen, L., Zhao, Y. \& Qin, X. Some aspects of high manganese twinning-induced plasticity (TWIP) steel, a review. Acta Metall. Sin. 26, 1-15 (2013).

110. Güvenç, O., Roters, F., Hickel, T. \& Bambach, M. ICME for crashworthiness of TWIP steels: from ab initio to the crash performance. JOM 67, 120-128 (2015).

111. Sun, $F$. et al. Deformation microstructure and mechanisms in a metastable $\beta$ titanium alloy exhibiting TWIP and TRIP effects. Mater. Sci. Forum 783-786, 1360-1365 (2014).

112. Hong, D. H., Lee, T. W., Lim, S. H., Kim, W. Y. \& Hwang, S. K. Stress-induced hexagonal close-packed to face-centered cubic phase transformation in commercialpurity titanium under cryogenic plane-strain compression. Scr. Mater. 69, 405-408 (2013).

113. Springer, H., Baron, C., Szczepaniak, A., Uhlenwinkel, V. \& Raabe, D. Stiff, light, strong and ductile: nano-structured high modulus steel. Sci. Rep. 7, 2757 (2017).

114. Miller, W. S. et al. Recent development in aluminium alloys for the automotive industry. Mater. Sci. Eng. A 280, 37-49 (2000).

This seminal contribution provides a critical overview of the use of aluminium as a structural material in cast, extruded or sheet conditions.

115. Mordike, B. L. \& Ebert, T. Magnesium properties-applications-potential. Mater. Sci. Eng. A 302, 37-45 (2001).

116. Marlaud, T., Deschamps, A., Bley, F., Lefebvre, W. \& Baroux, B. Influence of alloy composition and heat treatment on precipitate composition in $\mathrm{Al}-\mathrm{Zn}-\mathrm{Mg}-\mathrm{Cu}$ alloys. Acta Mater. 58, 248-260 (2010).

117. Starke, E. A., Sanders, T. H. \& Palmer, I. G. New approaches to alloy development in the Al-Li System. JOM 33, 24-33 (1981).

118. Suzuki, A., Saddock, N. D., Jones, J. W. \& Pollock, T. M. Solidification paths and eutectic intermetallic phases in Mg-Al-Ca ternary alloys. Acta Mater. 53, 2823-2834 (2005).

119. Sandlöbes, S. et al. A rare-earth free magnesium alloy with improved intrinsic ductility. Sci. Rep. 7, 10458 (2017).

120. Sandlöbes, S., Zaefferer, S., Schestakow, I., Yi, S. \& Gonzalez-Martinez, R. On the role of non-basal deformation mechanisms for the ductility of $\mathrm{Mg}$ and $\mathrm{Mg}-\mathrm{Y}$ alloys. Acta Mater. 59, 429-439 (2011)

121. Counts, W. A., Friák, M., Raabe, D. \& Neugebauer, J. Using ab initio calculations in designing bcc MgLi-X alloys for ultra-lightweight applications. In Advanced Engineering Materials Vol. 12 (ed. Quandt, E.) 1198-1205 (Pergamon, 2010). 


\section{Review}

122. Zhu, L., Li, N. \& Childs, P. R. N. Light-weighting in aerospace component and system design. Propuls. Power Res. 7, 103-119 (2018).

123. Kalidindi, S. R. \& De Graef, M. Materials data science: current status and future outlook. Annu. Rev. Mater. Res. 45, 171-193 (2015).

124. Shao, C. W. et al. Improvement of low-cycle fatigue resistance in TWIP steel by regulating the grain size and distribution. Acta Mater. 134, 128-142 (2017).

125. Niendorf, T. et al. Functionally graded alloys obtained by additive manufacturing. Adv. Eng. Mater. 16, 857-861 (2014)

126. $\mathrm{Xu}, \mathrm{W}$. et al. Ti-6Al-4V additively manufactured by selective laser melting with superior mechanical properties. JOM 67, 668-673 (2015).

127. Long, J. et al. Improved fatigue resistance of gradient nanograined Cu. Acta Mater. 166, 56-66 (2019).

128. Terada, D., Houda, H. \& Tsuji, N. Effect of grain size distribution on mechanical properties of ultrafine grained Al severely deformed by ARB process and subsequently annealed. J. Phys. Conf. Ser. 240, 012111 (2010).

129. Kim, S. I. et al. Dense dislocation arrays embedded in grain boundaries for highperformance bulk thermoelectrics. Science 348, 109-114 (2015).

130. Kim, S. W., Li, X., Gao, H. \& Kumar, S. In situ observations of crack arrest and bridging by nanoscale twins in copper thin films. Acta Mater. 60, 2959-2972 (2012).

131. Suresh, S. Graded materials for resistance to contact deformation and damage. Science 292, 2447-2451 (2001)

132. Ho, S. \& Lavernia, E. J. Thermal residual stresses in functionally graded and layered 6061 Al/SiC materials. Metall. Mater. Trans. A 27, 3241-3249 (1996).

133. Carpenter, J. S., McCabe, R. J., Mayeur, J. R., Mara, N. A. \& Beyerlein, I. J. Interface-driven plasticity: the presence of an interface affected zone in metallic lamellar composites. Adv. Eng. Mater. 17, 109-114 (2015).

134. Akasheh, F., Zbib, H. M., Hirth, J. P., Hoagland, R. G. \& Misra, A. Dislocation dynamics analysis of dislocation intersections in nanoscale metallic multilayered composites. J. Appl. Phys. 101, 084314 (2007)

135. Knorr, I., Cordero, N. M., Lilleodden, E. T. \& Volkert, C. A. Mechanical behavior of nanoscale Cu/PdSi multilayers. Acta Mater. 61, 4984-4995 (2013).

136. Ma, Z. et al. Strength gradient enhances fatigue resistance of steels. Sci. Rep. 6, 22156 (2016).

137. Mozaffari, A., Danesh Manesh, H. \& Janghorban, K. Evaluation of mechanical properties and structure of multilayered $\mathrm{Al} / \mathrm{Ni}$ composites produced by accumulative roll bonding (ARB) process. J. Alloys Compd. 489, 103-109 (2010).

138. Tayyebi, M. \& Eghbali, B. Study on the microstructure and mechanical properties of multilayer $\mathrm{Cu} / \mathrm{Ni}$ composite processed by accumulative roll bonding. Mater. Sci. Eng. A 559, 759-764 (2013)

139. Salomon, S. et al. Combinatorial synthesis and high-throughput characterization of the thin film materials system Co-Mn-Ge: composition, structure, and magnetic properties. Phys. Status Solidi A 212, 1969-1974 (2015).

140. König, D., Eberling, C., Kieschnick, M., Virtanen, S. \& Ludwig, A. High-throughput investigation of the oxidation and phase constitution of thin-film Ni-Al-Cr materials libraries. Adv. Eng. Mater. 17, 1365-1373 (2015).
141. Carroll, B. E. et al. Functionally graded material of 304L stainless steel and Inconel 625 fabricated by directed energy deposition: characterization and thermodynamic modeling. Acta Mater. 108, 46-54 (2016).

142. Yin, S. et al. Hybrid additive manufacturing of Al-Ti6Al4V functionally graded materials with selective laser melting and cold spraying. J. Mater. Process. Technol. 255, $650-655$ (2018)

143. Muller, P., Hascoet, J. Y. \& Mognol, P. Toolpaths for additive manufacturing of functionally graded materials (FGM) parts. Rapid Prototyping J. 20, 511-522 (2014).

144. Hofmann, D. C. et al. Developing gradient metal alloys through radial deposition additive manufacturing. Sci. Rep. 4, 5357 (2014)

145. Li, W. et al. Fabrication and characterization of a functionally graded material from Ti-6Al-4V to SS316 by laser metal deposition. Addit. Manuf. 14, 95-104 (2017).

146. Knoll, H. et al. Combinatorial alloy design by laser additive manufacturing. Steel Res. Int 88, 1600416 (2017)

147. Robbins, J., Owen, S. J., Clark, B. W. \& Voth, T. E. An efficient and scalable approach for generating topologically optimized cellular structures for additive manufacturing. Addit. Manuf. 12, 296-304 (2016).

148. Murphy, C. (ed.) McKinsey Sustainability \& Resource Productivity Practice https://assets. mckinsey.com/ /media/FF702F8557624AD0884F116174A60298.ashx (McKinsey Global Institute, 2014).

149. de Pee, A. et al. Decarbonization of Industrial Sectors: The Next Frontier (McKinsey, 2018).

150. International Aluminium Association. Global aluminium cycle 2017. World Aluminium www.world-aluminium.org/statistics/massflow (2017).

151. Pauliuk, S., Milford, R. L., Müller, D. B. \& Allwood, J. M. The steel scrap age. Environ. Sci Technol. 47, 3448-3454 (2013).

152. Duke, R. Policy Options to Deeply Decarbonize American Industry. Discussion Draft for July 18, 2019 Brooking Institution Workshop (2019).

Acknowledgements E.A.O. acknowledges support from B. Reck in quantifying nickel flows.

Author contributions All authors contributed equally to this paper.

Competing interests The authors declare no competing interests.

Additional information

Correspondence and requests for materials should be addressed to D.R., C.C.T. or E.A.O. Peer review information Nature thanks Daniel Cooper, Elizabeth Holm, Gabriella Tranell and the other, anonymous, reviewer(s) for their contribution to the peer review of this work. Reprints and permissions information is available at http://www.nature.com/reprints.

(c) Springer Nature Limited 2019 